\title{
The analysis of the causes of slope-slide caused by mining and research of slope of stability and treatment measures
}

\author{
LIU Cuiran ${ }^{1, a}$, HOU Jinkai ${ }^{2, b}$ and GUO Jinjun ${ }^{1, c}$ \\ ${ }^{1}$ Luoyang Institute of Science and Technology, Luoyang, China \\ 2 Institute of Geology \& Mineral Resources Survey of HeNan, Luoyang, China \\ aliucuiran@163.com, b420974022@qq.com, cgjj2001616@126.com
}

Keywords: Mining slide slope, Reasons of slide slope, Mechanism of slide slope, Analysis of slope, Stability treatment of slide slope.

\begin{abstract}
Slope-slide caused by mining is a problem of mine geological environment treatment in our country. It is particularly important to analyze the reasons and mechanism of the mining slide-slope, and put forward the methods of analysis of stability of slope and corresponding countermeasures for reasonable exploitation and utilization of mineral resources and protection of geological environment. The paper emphasisly analyzed on reasons, mechanism, influential factors and control measures for slides slope in Henan province mining area. Results show that long-term monitoring is an important aspect. In addition, the formed slide-slope should be treated by comprehensive measure, such as grading, drainage, plant engineering and stabilization works.
\end{abstract}

\section{Introduction}

That slope rock mass produce the deformation under the effect of gravity and slide along the sliding face under is called landslide [1]. The stability of slope is often affected by various elements such as rainfall, snow and the distribution of man which cause unbalance of slope and slide causing damage of environment and economy. So, it is very important to monitor, do stability analysis, manage the slope and refrain from landslide. In view of this, the causes of landslide of some mining area of in Henan Provience are explored and the rock slope stability calculation and analysis are done in Baofeng bauxite mining area and put forward the measures of landslide control, avoiding cause huge economic losses, even human lives in the article [1].

\section{Analysis of causes and influential factors of mining landslide}

\subsection{Analysis of causes of mining landslide}

Landslide is one of geological disasters of metal and nonmetal mines mining. The two types of landslide are slag landslide and shaped coal mining slope landslide. The causes of slides are listed as following.

The landslides caused by unreasonable mining. Stripping ratio is not according to the requirement of the strip mining design. Mining face steep or excavation orebody from middle develop rear unloading tension crack and induced landslides under blasting and vibration of the vehicle. Especially, these conditions exist in the most typical limestone exploration area, such as JiuLiShan in Jiaozuo region, PuGong mountain in Xixian country, Wuliang town limestone mining area in Yuzhou city. The lower strata of orebody is taken out and the upper rock fall in some mining area [2].

Empress mountain landslide is a typical example in PingDing mountain coal mining district.Empress mountain landslide is located in PingDing mountain Shilong district. Because of the influence of fault, the underground coal is steep. With the mining coal of QingCao , mountain cracking occurs and severe instability of slope develop and the mine and residents Wells are in the serious deformation. A number of fissures of the ground develop in slopes, width is $1.5 \sim 3 \mathrm{~m}$ in commonly, the maximum width of $3.5 \mathrm{~m}$, the mountain generally down $2 \sim 5 \mathrm{~m}$, up to $10 \mathrm{~m}$. The four 
of the big cracks intermittently extend about $4500 \mathrm{~m}$ throughout the entire upper QingCaoLing Empress mountain area is a larger landslide, about $500 \mathrm{~m}$ long, as shown in figure 1.It directly threats to the 207 national road and the deformation of 207 national highway slope happened [3].

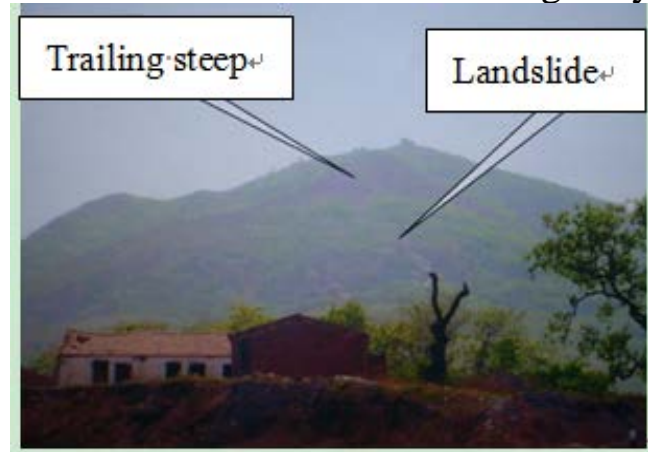

Fig.1 The landslide on the east hillside of Niangniang hill in Pingdingshan coal mine

Mine layout and slag heap are unreasonable. Some mining layout is unreasonable. The excavation at the foot of orebody and on the top is overlapped construction. The mining processing centers layout is too dense, stripping waste rock loose material is accumulated. The height of these loose materials is above $20 \mathrm{~m}$ with angle of greater 30 degree. These slopes are prone to slide with the vibration or rain excitation. The region of a loose landslide is circled in red line in Figure 2 [4].

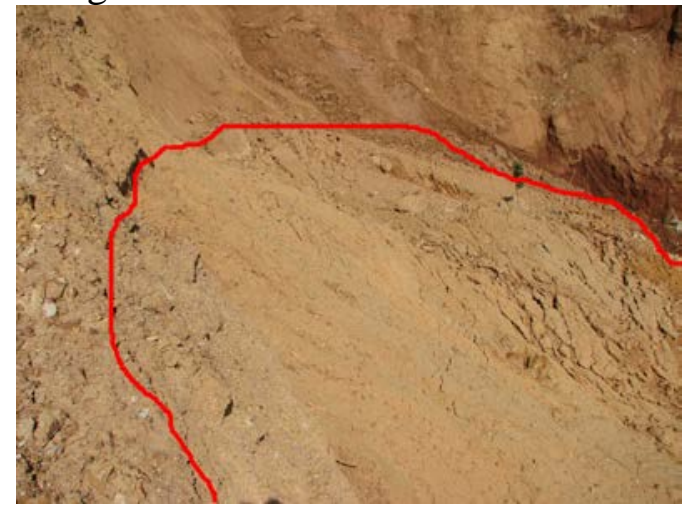

Fig.2 The loose landslide body in Ganshiya bauxite mine

The confused order of mining. The management of many small scale mines is out of control and the phenomenon of unplanned dig is common. Thus the mineral resources are destroyed and landslides are easy to trigger. These phenomenon is various in iron ore, bauxite, gold, limestone mining [2].

\subsection{Analysis of influence factors and triggering mechanism of mining landslide}

The formation of the landslide is closely related to inside and outside geologic forces. In mining area, the influence factors of landslide include dynamic action and artificial digging force and seepage deformation effect and water etc.

The above factors can be as a trigger mechanism triggering landslides. The dynamic action can change the stress state of rock and quickly lead to the occurrence of landslides. Groundwater function change the structure and strength of the sliding bed of slope rock and form deformation, resistance is reduced, eventually make the soil sliding. Water may wash toe of slope, cause internal stress changes, reduces the anti-sliding ability and induced landslides. According to the survey, the mining landslides are mostly related with the above factors.

\section{The evaluation of landslide stability}

A lot of evaluation methods of landslide stability can be divided into two kinds of qualitative analysis and quantitative calculation. The combination of qualitative analysis and quantitative calculation is needed when the landslide stability evaluation is done to check each other and achieve accurate target. 
Qualitative analysis is an approximate method determining transformation of landslide deformation and damage mode according to the deformation and failure mode and shape characteristics and geological structure and certain means of analysis, such as plane projection analysis method, the water pressure experiment method, etc.

There are many quantitative calculation of the stability of the landslide. In general, they can be divided into two categories. The one is limit equilibrium theory in which the landslide is as a whole. The other kind is numerical simulation method, which characteristic is the discretization. It is obvious that the numerical simulation calculation method is more conforms to the actual situation, because a landslide of the material properties of each component is not necessarily the same. The calculation is very complicated after discretization, so it is completed .mostly with the help of the related software. Currently used numerical simulation software are mainly ANSYS software which is based on the theoretical of finite element method and FLAC software [5-8]which is based on limited inserted theory. The following rock slope stability calculation analysis is done with FLAC software.

\subsection{Calculation model is set up}

The geometric dimensions are shown as in figure 3 and the physical and mechanical parameters of slope rock mass are shown in table 1.

The next step is the division of the next unit grid. Grid size determines the accuracy of the calculation results, but to choose a suitable number of unit is a complicated problem.

At last, the material properties and boundary conditions were determined. Material properties are identified with elastic-plastic model and conform to failure criterion using Mohr - Coulomb criterion. The natural slope is taken as free boundary and other boundary are for the fixed boundary. At the same time, in order to make the boundary conditions to be close to reality, the model of fixed boundary are done extended outward as shown in figure 4.

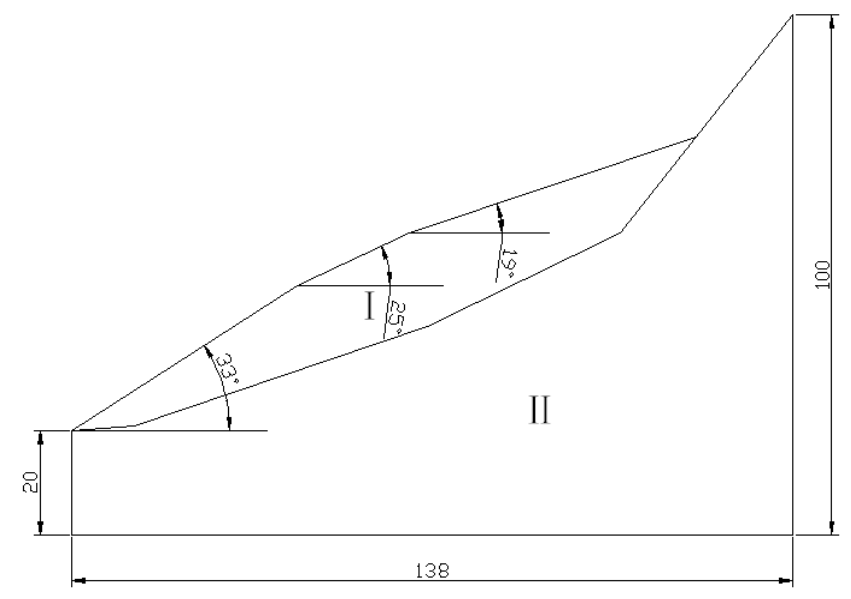

Fig.3 The vertical section figure of the slope

Table 1 The parameters of the slope

\begin{tabular}{|c|c|c|c|c|c|c|}
\hline $\begin{array}{l}\text { Parameters } \\
\text { number }\end{array}$ & $\begin{array}{c}\text { Density } \\
\left(\mathrm{Kg} / \mathrm{m}^{3}\right)\end{array}$ & $\begin{array}{c}\text { Bulk modulus } \\
(\mathrm{GPa})\end{array}$ & $\begin{array}{c}\text { Shear modulus } \\
(\mathrm{GPa})\end{array}$ & $\begin{array}{c}\text { Cohesion } \\
(\mathrm{MPa})\end{array}$ & $\begin{array}{c}\text { Friction angle } \\
\left({ }^{\circ}\right)\end{array}$ & $\begin{array}{c}\text { Tensile strength } \\
(\mathrm{MPa})\end{array}$ \\
\hline $\mathrm{I}$ & 2000 & 0.01 & 0.6 & 0.06 & 25 & 0 \\
\hline$I I$ & 2200 & 0.1 & 1 & 10 & 50 & 10 \\
\hline
\end{tabular}

\subsection{Calculation and result analysis}

FLAC software can calculate safety coefficient using SOLVE FOS command by reducing the strength. The method of calculation reduces the strength of the material in some way until failure surface appears in the slope. Friction Angle and cohesive force decrease according to the constant factor at the same time, the FLAC software can automatically get each group strength parameters in the same way, and calculate the find safety coefficient. The safety coefficient of the program is $\mathrm{K}=$ 
1.71 which shows the slope is in safe and stable state. However, the degree safety of the slope is not high. Under certain conditions, such as weathering, vibration, rainfall and human disturbance, etc., the slope can instability and landslide. The calculated velocity vector and shear strain nephogram are shown in figure 5.

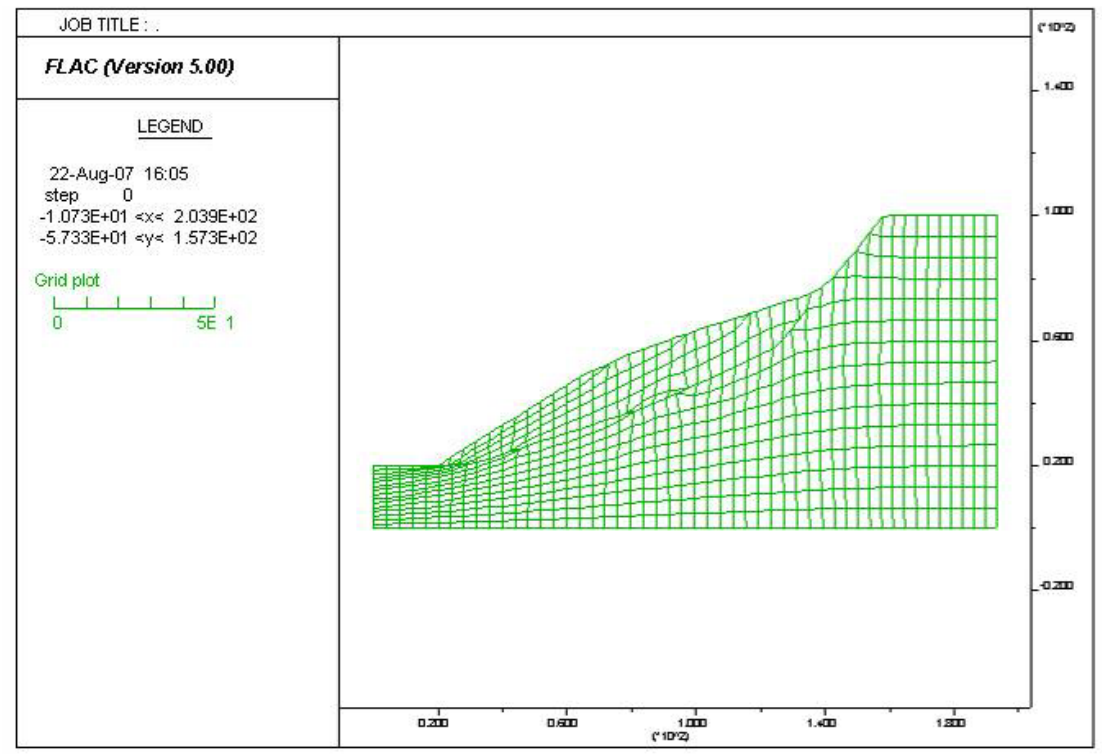

Fig.4 The computational model of the slope

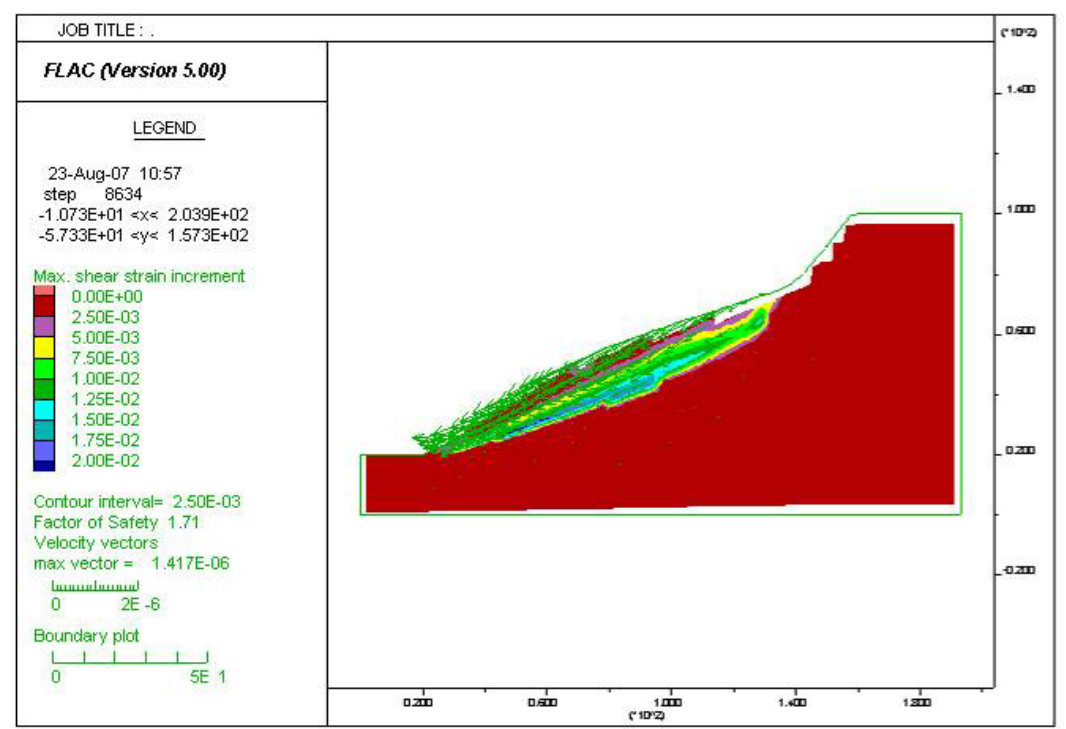

Fig.5 The velocity vector and shear strain increment figure

\section{Studies treatment measures of the landslide}

\subsection{Landslide monitoring}

Landslide deformation monitoring and forecast projects are more and more are paid attention. There are three purposes for landslide monitoring. One is the correct decision and evaluation for the stability of the landslide and forecast for protecting the environment, buildings and people's life and property. The second is to provide scientific basis for prevention and control of landslide. The third is to predict the future development trend of the displacement and deformation after the treatment. The main monitoring contents include sliding displacement, inside and outside of the underground water level, water temperature, water quality and groundwater flow rate and water temperature changes, the pore water pressure and its dissipation and growth and pressure on the retaining structure. 


\subsection{Prevention countermeasures for the mining landslide}

The main principle in treatment mining landslide is priority prevention. According to the different situation, the following measures can be adopted [10].

(1)Rational mining layout is key in prevention of landslide, such as adopting design mining stripping ratio for benching, gentle slope and short slope height, etc.

(2)Residual soil should be stacked on reasonable position and control of waste residue pile slope. The excavation of slope should be supported in a timely manner using waste rock waste residues.

(3)Find out as much as possible instability factors for the slope and take timely measures to eliminate the adverse factors. For a big, long-term instability or hidden trouble of slope, long observation should be taken to ensure safety.

(4)If the deformation has appeared, the engineering measures such as anti-slide pile should be taken according to different characteristic of failure. Rainfall can cause to landslide, so drainage and dry measures is suit to protect the slope. Reducing the top load for push-type and strengthening the foot of slope are effective.

\section{Summary}

Mining landslide is a geological disaster under the influence of man-made factors. For mining landslide, it is not only to use with the traditional engineering geological survey methods, but also combine with physical and mechanical testing by various kinds of advanced instruments and equipment. At first, find out the causes of formation and related geometric elements, physical and mechanical parameters of slope. Then choose reasonable method to analyze stability of slope. According to the analysis result and geological conditions, the economic and reasonable governance measures should be determined. At last, the further observation is needed to test the effect of governance.

\section{Acknowledgements}

This work was supported by Henan province university science and technology innovation team support program funded projects (14IRTSTHN029).

\section{References}

[1] Sun X J, Wan L H,Li Z P etal. Engineering and hydrologic environment Geology Mechanics [M].BeiJing: Science Press, 2001.

[2] Wu G C, Zhen X C. Henan mine environment question research [M] .BeiJing: Chinese Press, 2007.

[3] Henan Geological \&Mining Resource Construction Engineering (Group) Co., LTD, Pingdingshan Coal (Group) Co., LTD. Henan pingdingshan coal mining area geological environment survey[R], 2002.

[4] Department of Land and Resource of HeNan Province, North China University of Water Resource and Electric Power.Research of warning technology of ecological and geological environment of bauxite of Henan BaoFeng GanShi cliff[R], 2006.

[5] Liu H D. Slope stability prediction theory and method[M].ZhengZhou: The Yellow River Water Conservancy Press, 1996.

[6] Carrara A.Multivariate models for landslide hazard evaluation[J]. Mathematical Geology,1983,15(3):403-426.

[7] Cui Z Q, Li N. Slope engineering theory and the latest development[M].BeiJing: China's water resources and hydropower Press, 1999. 
[8] Chen Z Y The soil slope stability analysis: principle, methods, program [M].BeiJing: China's water resources and hydropower Press, 2001.

[9] Liu C Z. Prospecting guide geological disasters [M].BeiJing: Geological publishing house, 2000.

[10] Hou J K. The study of the analysis of main environment problems caused by mine exploration and the prevention and control countermeasures .ZhengZhou: Civil Department of North China University of Water Resource and Electric Power, 2007. 